\title{
EDITORIAL
}

\section{AJEE Special Issue Ecologising Education: Storying, Philosophising and Disrupting}

... I wonder whether the process ordinarily referred to as growing up is not actually a process of growing down; whether experience, so much touted among adults as the things children lack, is not actually a progressive dilution of the essentials by the trivialities of living. This much at least is sure: my earliest impressions of wildlife and its pursuit retain a vivid sharpness of form, color, and atmosphere that half a century of professional wildlife experience has failed to obliterate or to improve upon. (Leopold, 1949, p. 120)

Over the last decade there has been a discernable global upsurge of nature kindergartens, forest schools, bush schools and nature-based primary schools; all with varying degrees of intent focused on (re)connecting children and young people in/with/as nature. Yet, not all of these educational endeavours are the same. The understanding of the role the natural world might play in pedagogy varies, the desire to work within the system or radically change it shifts according to commitments and philosophies, and the perceived divide, or lack thereof, between child and nature also has significant effects on curriculum and content. Still, there is a shared commitment among these educational movements to change existing relationships with nature and education. There is a desire and much work being done to ecologise education. In this Special Issue, with its primary focus on the west coast of Canada, we offer a pause to story, philosophise, expand, and disrupt as this 'type' of education presents a significant shift and fundamentally questions what school is and what education is for.

All of the articles in this special issue tell the story of challenging the status quo, of working with community (both human and more-than), all the while humbly recognising that this work takes time, mistakes will be made, and that there is still so much more to learn and do if we are really going ecologise education. In this issue we have divided the papers into two sections; while there is significant overlap between sections, the first grouping emphasises stories of practice. These span the close-up narratives of a single classroom, a particular encounter, and a lone parent to the experiences of starting schools and programs where none were before. The four papers in this section share some important themes centred around the idea of changing the culture of conventional forms of schooling in order to build relationships and make education more ecologically immersed and responsive.

The first theme that appears in all four of the articles is an orientation that we might best describe as humble. There is a clear sense that the human teacher must assume a lesser role, moving away from the role of centralised expert towards one of co-teacher, learning facilitator, fellow traveller, and even pedagogical discoverer. In none of these articles, in spite of all the time spent in the field as teachers and researchers, does one get the sense that the authors feel like they are 'experts' or that they are proposing a form of 'best practices'. They are sharing their experiences, their trials and tribulations, their discoveries, in the hope that this work might inspire, support, challenge 
others to create something or extend their own practices in their places and ways. This humility extends to the program design conversations as we hear authors having to constantly adjust programs and pedagogies as new issues come to light. It appears that one of the challenges for this kind of substantive change in educational work is that one must operate not knowing fully what the world will entail that we are teaching our learner towards. This leads directly into the second theme, which is one of having to notice and at times challenge the status quo. This status quo takes many forms, from the norms and ways of doing things within the institutions and systems in which the work is happening, to the recognising and responding to the limits of understanding that parents, other teachers, the learners, and even the authors themselves have with regard to what is both possible and what is getting in the way of making that vision happen.

A third and quite compelling theme of these four papers has to do with the relationship the authors have and are developing with the more-than-human world. We get a glimpse into how they are tuning themselves differently in order to listen and work with the more-than-human world and the importance they are placing on the process of relationship development for their students as well. This work is clearly being placed in the outdoors, time is being dedicated to it, and the language employed in these articles moves the metaphors generally employed to talk about the natural world in interesting directions. For these educators, the natural world is an active/interactive teacher and learner, a partner in the teaching process, an agent for change. That which is encountered has rights, stories and ways of being that are worth considering and that places interesting limits on what is permissible and on anthropocentrism writ large. The natural world is involved in learning about and from us as well, and this has deeper implications for knowledge and meaning as ecologising education continues. All of this work appears to thoughtfully move the locations where this work is happening out of the background and away from being a backdrop into the foreground and as collaborator. It is interesting to consider how the schools and early years settings and their grounds, curricula and pedagogy are changing as a result.

A fourth and final theme that we thought important to draw attention to is the continuing thread of community, of building alliances, of ongoing support. None of these educational projects described in these articles appears to be happening without support. For some, it is the presence of a key administrator, a committed group of parents or an active natural world, but it is also apparent how much the literature of field has supported and enriched the teaching and creating that all the authors are engaged. We hope that this group of offerings continues and inspires that process.

In the first article, Piersol, Groves, and Russell explore some of the disruptions that were necessary and unexpected, positive and troubling, employed and encountered during the creation of one of the first multi-age, ecological, public school programs in Canada. The reader gets a sense of the complexity of the work but also how deeply political it is as well. This story of success and indeed challenge led the teachers in the program to understand themselves to not only be interested in being outdoors, building rich learning environments and deepening relations for their students, but also as agents of change in an educational world that tends not to give the natural world a second thought.

In the second article, in concert with the first, Elliott and Krusekopf tell a careful story of the creation of one of the first nature kindergartens in Canada. We hear of the power of community and the role that imaginative risk taking must play in the process. We also come to understand the importance of a clear shared vision and the role of allies within the larger system. This article sheds light on important considerations in terms 
of doing this type of work that are only earned through years of hard work and deep care.

In their article, Dawson and Beattie tell the story of an early childhood class and an encounter with three bald eagles. Positioning this kind of an encounter as a magical moment, they proceed to explore the moment and name what they construe as the necessary components of relationship and pathic knowledge, defined as an understanding of rather than about place. This work allows the authors to further suggest a pedagogy of responsiveness and surrender to an active agential place and its denizens while allowing that place to take on a role as teacher for students and human teachers.

The final article in this section, relating to practice, focuses on a mother and a young child as they come to create their new relationship with each other while locating it in place. In their article, Humphreys and Blenkinsop explore what it might mean to extend the metaphor and practice of nature as active teacher to one of co-parent as well. Using close observation and some powerful journal entries, the authors track the development in and engagement with several key natural places that further allows them to comment on ecological identity, empathy, experiential learning, and the affordances of the natural world.

In the second section, the three papers all take a step back from the practice of ecologising education and instead focus on various challenges that make the act of theorising with, engaging in, and researching about this kind of educational change difficult to bring to fruition. From the particular to the more general, all three articles suggest potential changes in some of the taken-for-granted cultural, institutional, and research assumptions that need to be named and responded to if this work is going to have success on a larger scale.

The first theme that appears in this group of articles is a commitment to continue to push against, expand, and extend that which is currently accepted. This includes extending and critiquing the research of the field, noticing the gridlines that restrict possibilities, and naming the practitioner and field as agents of change. The sense one gets when reading the work in this section is that there is a demand being placed on environmental educators not only to be concerned with building relationships to the natural world but also to be advocates for ecologising education; to be thoughtfully critical of the ways and assumptions of current practices and theories, and to position oneself politically and carefully in the work. This leads into the second theme wherein all three papers see at least part of the challenge for environmental educators to be about recognising culturally imposed limitations. The authors speak to ways in which such limitations act to undervalue the natural world, or to push us out of relation with the more-than-human, or to direct us into ways of being that make particular interactions between humans and the other-than-human at the very least difficult, if not downright impossible.

A third theme that comes through in all three of these papers is that even though there are some quite sizable assumptions, barriers, and limitations to ecologising education we are not alone in any way shape or form. All three articles draw on a variety of sources that support and improve their work and all are able to see concrete actions that can be taken, even as very first steps, by educators at any place in their ecologising trajectory. Far from being a descent into the hopelessness of an unimaginably difficult project there is possibility thoughtfully etched throughout. Further to this, the reader gets a sense that this work is inclusive, that educators will need to engage their minds, their imaginations, their relations, their bodies, and so on. Also worth noting is how all of these papers are in some ways breaking with what might be the historical traditions of doing research and offering it up in an academic venue. Stories and vignettes are used not only to make educational points but to bring different voices and ways of knowing 
into the discussion. Authors position themselves differently in relation to the ideas, the readers, and the natural world. And there is a clear sense that these ideas are being offered not as fully formed truths but as starting points (mirroring the articles in the previous section), offerings to be build upon, and living theories in need of further sustenance. It is apparent that these articles are in the process of trying to practise what it is they are preaching.

The opening article of this section is an offering of a set of touchstones that are important to what the authors, Jickling et al., are calling wild pedagogies. Pushing back against what they see as a modernist move to control the natural world, the educational system and the wild freedom of the learner, they propose and go on to explore these touchstones. Intriguingly, each touchstone appears, though expressly named, in various incarnations and enunciations in all of the other papers in this special issue.

In their article, Gerofsky and Ostertag suggest drawing inspiration and ideas from a range of teacher tropes. They begin by noting the metaphorical and physical power the straight line has in shaping much of education. From boxlike classrooms to linear notions of knowledge development, to the hierarchies of control, there is deep commitment to organised alignment that might be limiting the possibilities of a more abundant, storied, fecund, rhisomatic education. Engaging with clowning, taking up a physical practice (e.g., dance or parkour), teaching in a garden, or examining the alter-global movement, all provide ways for the ecologising educator to not only see the gridlines that restrict possibility and shape our practices but also to find ways to resist, to step outside, and teach beside and beyond the status quo.

The last article in this group focused on change in environmental education, by Siegel, Cutter-Mackenzie-Knowles, and Bellert, seeks to update one of the most cited pieces of research in the last 15 years. In trying to update Kollmuss and Agyeman's 'Mind the gap', the authors make it clear how much the field has changed since 2002. Weaving threads that draw from the very practical, what it means to act in proenvironmental ways, to the deeply philosophical, how our understandings of nature have changed as a result of recent theorising, the authors demonstrate that a new model of environmental education might be useful. And into that gap they offer a re/storying.

This is an exciting and eclectic group of papers that are all drawn together around a sense of wanting to ecologise education in sophisticated and substantive ways. We hope you find ideas, inspirations, and maybe even a few challenges that benefit and grow your practices and theories.

\section{Reference}

Leopold, A. (1949). A Sand County almanac and sketches here and there. Oxford: Oxford University Press.

Laura Piersol, Sean Blenkinsop \& Amy Cutter-Mackenzie-Knowles 